\title{
The effect of moisture on the mechanical response of wood, adhesive and their interphase by means of nanoindentation
}

\author{
Axel Rindler ${ }^{1,2}\left(\right.$ Christian Hansmann ${ }^{1} \cdot$ Johannes Konnerth $^{1,2}$
}

Received: 15 October 2018 / Published online: 15 May 2019

(c) The Author(s) 2019

\begin{abstract}
The single sections of a wood/adhesive bond, namely the adherend wood, the pure adhesive and the interphase are expected to contribute differently to the mechanical behaviour of a joint. Moisture-related changes of the stress/strain states between the adherends tend to result in deformation or even material failure. Therefore, beside the elastic, the moisture-related mechanical properties of the involved components are of significant interest. Adhesively bonded samples of spruce (Picea abies) using adhesives that are common in furniture and flooring production (emulsion polymer isocyanate (EPI), polyvinyl acetate (PVAc), urea formaldehyde (UF) and ultra-low formaldehyde-emitting amino resin (ULEF)) were manufactured under laboratory conditions. Quasi-static nanoindentation was performed on the pure adhesive polymer, the S2 layer of pure wood cells and interphase wood cells, to obtain the reduced elastic modulus, hardness and the indentation creep. To investigate the moisture-related mechanical properties, the testing environment was held under constant temperature and different controlled humidity levels. The pure wood cell walls generally tend to show a more stable behaviour to humidity changes than the investigated adhesives. It can be assumed that the ULEF adhesive penetrated the cell walls, as differences between pure wood cells and those located in the interphase could be identified. EPI, PVAc and UF showed no evidence of modifying the interphase cell walls but revealed different behaviours in relation to pure wood cells.
\end{abstract}

Axel Rindler

a.rindler@wood-kplus.at

1 Wood K plus - Competence Centre for Wood Composites and Wood Chemistry, Altenberger Strasse 69, 4040 Linz, Austria

2 Department of Material Sciences and Process Engineering, Institute of Wood Technology and Renewable Materials, BOKU - University of Natural Resources and Life Sciences - Vienna, Konrad Lorenz-Strasse 24, 3430 Tulln, Austria 


\section{Introduction}

An adhesive layer of a solid wood bond consists, beside the pure adhesive polymer, of multiple sections that are participating differently to the total performance of an adhesive joint (Eckmann 2007; Marra 1992). Moisture-driven swelling and shrinking of the adherends, but also external loads lead to different stress and strain states within the joint and may lead to considerable interfacial stress between the adhered components (Gindl et al. 2005). Depending on the adhesive structure and its interaction with the adherend, the adhesive layer and/or the adherend is expected to compensate these stresses and respond with elastic, viscoelastic or non-reversible (plastic) deformation (Frihart 2009; Frihart and Wescott 2008).

Elastic as well as viscoelastic properties of polymers are known to be significantly influenced by polymer type (cross-linking density), temperature, but also absorbed moisture in the polymer (Brockmann et al. 2008; Habenicht 2002). The capability of absorbing water vapour (Wimmer et al. 2013) and the mechanical response to this have been experimentally demonstrated for cured adhesive polymers present in adhesive joints for different temperatures and relative humidities as reported in the previous studies (Jakes et al. 2015; Konnerth and Gindl 2008; Rindler et al. 2018; Stöckel et al. 2013).

In addition, for different wood species, moisture- and temperature-related elastic, viscoelastic and plastic micromechanical behaviour is described, and data are available in the literature (Gindl et al. 2004; Gindl and Schöberl 2004; Wagner et al. 2015; Wimmer et al. 1997; Zickler et al. 2006), whereas for the interphase region, data are relatively scarce. The interphase is assumed to contribute to the performance of the adhesive joint.

Thus, moisture-induced changes in the mechanical behaviour of the interphase region, where the adhesive infiltrates the wood structure, are of significant interest. The interphase region is essential for the adhesive joint performance and its geometry varies, i.e. with the used adhesive, its viscosity, molecular weight distribution and solid content, the wood anatomy and the species porosity, the pressing parameters and involved surface energy (Kamke and Lee 2007; Suchsland 1958). In general, the wood/adhesive interphase is geometrically defined with the surface of the adherend on the one side and with adhesive-penetrated wood cells on the other side, while the maximum penetration depth in the wood adherend is locally variable. According to Frihart (2009), wood adhesives can be divided with regard to their structural properties and their interaction with wood into two groups: in situ polymerized adhesives and pre-polymerized adhesives. In situ polymerized adhesives, i.e. urea formaldehyde (UF), melamine-urea formaldehyde (MUF), phenol-formaldehyde (PF), etc., generally exhibit an average molecular weight (MW) of less than $2000 \mathrm{~g} / \mathrm{mol}$ (Frihart 2009) and often infiltrate the cell wall before curing. Pre-polymerized adhesives, i.e. polyvinyl acetate (PVAc), emulsion polymer isocyanate (EPI), polyurethane (PUR), etc., usually are of higher MW that prevents a penetration of the cell wall. Although these adhesives already have fractions of high MW at the time of application, the main 
curing step (i.e. cross-linking of EPI) occurs during the application. On the other hand, these adhesives offer a flexible backbone what makes them less rigid and more flexible to dimensional changes (Frihart 2009) within the adhesive layer.

From a mechanical point of view, the interphase is the region where stress is transferred from the adherend into the adhesive polymer (Frihart 2004). Here, it is of interest whether the adhesive is capable of penetrating into the wood cell wall, thus creating a composite with modified swelling and shrinkage behaviour as well as altered micromechanical properties compared to a pure wood cell wall.

The impact of adhesive penetration into the microstructure on the macroscale bond behaviour of various bond types was repeatedly confirmed with high-sensitive deformation measurement methods (Müller et al. 2005) and numerical modelling (Serrano and Enquist 2005). Beside these techniques, UV microscopy (Gindl et al. 2002), X-ray tomographic microscopy (Hass et al. 2012; McKinley et al. 2018; Paris and Kamke 2015; Paris et al. 2014), electron energy loss spectroscopy (Rapp et al. 1999), confocal laser scanning microscopy (Xing et al. 2004), scanning thermal microscopy (Konnerth et al. 2008) and Raman spectroscopy (Konnerth et al. 2009) were successfully used for observing and quantifying the penetration behaviour of different wood adhesives. A comparative study on the penetration behaviour of adhesives into red oak (Quercus rubra), hybrid poplar (Populus deltoids $\times$ Populus trichocarpa) and Douglas fir (Pseudotsuga menziesii) was conducted by means of fluorescence microscopy, scanning electron microscopy (SEM), backscatter imaging (BSE), wavelength-dispersive spectroscopy (WDS) and X-ray tomography (XMT) (Modzel et al. 2011).

For determining the mechanical properties of interphase wood cell wall layers in situ, nanoindentation (NI) turned out to deliver satisfying results. Measurements of melamine-modified spruce (Gindl and Gupta 2002) and spruce glued with MUF/PRF (Konnerth and Gindl 2006) and MUF/UF (Stöckel et al. 2010) by means of NI revealed a considerable increase in the mechanical properties of the secondary cell wall S2, while other adhesives were not able to bias mechanical properties of cell walls as a result of adhesive penetration. A combination of quasi-static NI and synchrotron-based X-ray fluorescence microscopy (XFM) was used to successfully map and quantify the infiltration of phenol formaldehyde (PF) into loblolly pine (Pinus taeda) latewood cell walls by moisture-related reduced elastic modulus and hardness (Jakes et al. 2015).

A further development of NI enabled to observe the adhesion behaviour between wood and adhesive directly at the interface of the two components. Therefore, a specific NI testing methodology was developed to obtain mechanical information on the adhesion performance of different cell surfaces of spruce fibres in contact with cured UF (Obersriebnig et al. 2012), MUF and PUR (Herzele et al. 2018). With these approaches, an improved understanding of the adhesion properties of different adhesives to the local available surface areas of wood cells could be gained. For most approaches described above, ambient conditions were used.

Knowledge of the moisture-dependent elastic and viscoelastic properties, especially of the interphase region, is scarce, but it is expected to contribute to the awareness of the adhesive joint behaviour under different humidities. 
The aim of the present study is to analyse the moisture-related mechanical properties of the wood/adhesive interphase of selected in situ polymerized and prepolymerized wood adhesives by means of quasi-static nanoindentation. Therefore, the individual wood components (penetrated cells, non-penetrated cells) present in an interphase of spruce wood adhered with different adhesives were investigated using different climate conditions, representing a typical range occurring in interior applications, relevant for, for example, furniture and flooring systems (Rapp et al. 2011). Wood interphase data were combined with mechanical data from cured adhesive polymers present in those bonds already analysed and published in an earlier study (Rindler et al. 2018).

\section{Materials and methods}

\section{Sample preparation and conditioning}

Adhesively bonded wood specimens as used for indentation were prepared by using axially split and planed spruce lamellas (Picea abies). For this study, four different adhesives were used to adhesively bond the samples: a low-emitting urea-formaldehyde resin (UF; Cascorit 1274 and hardener 7500, AkzoNobel N.V., Amsterdam, Netherlands), an ultra-low formaldehyde-emitting amino resin (ULEF; LignuPro Zero A201 and hardener H203, AkzoNobel N.V., Amsterdam, Netherlands), an emulsion polymer isocyanate (EPI; Cascolit 4421 and hardener 2556, AkzoNobel N.V., Amsterdam, Netherlands) and a polyvinyl acetate (PVAc D3; Jowacoll 103.84, Jowat SE, Detmold, Germany) adhesive. All the used adhesives are especially designed for solid wood bonding for pressing temperatures below $100{ }^{\circ} \mathrm{C}$ and do not necessarily represent adhesive systems based on similar chemistry but used for different applications, i.e. particleboard or fibreboard.

For the adhesion, spruce lamellas $\left(150 \times 100 \times 7 \mathrm{~mm}^{3}\right)$ were equilibrated at standard climate conditions $\left(20^{\circ} \mathrm{C}, 65 \% \mathrm{RH}\right)$, planed to $5 \mathrm{~mm}$ thickness and adhesively bonded at their tangential anatomical planes within $24 \mathrm{~h}$ after planing. The specific processing conditions recommended by the adhesive manufacturers were considered. In accordance with EN 302-1:2013, an angle between the growth rings of the two lamellas and the adhesive polymer between $30^{\circ}$ and $90^{\circ}$ was established.

The main parameters for bonding (pressing temperature, time and pressure) were selected as suggested by the adhesive manufacturer, with the intention to minimize moisture differences between the specimen and keeping pressing times low. Here, for the EPI system $20{ }^{\circ} \mathrm{C}, 420 \mathrm{~s}$ and $0.8 \mathrm{MPa}$ and for all other adhesives $90{ }^{\circ} \mathrm{C}, 60 \mathrm{~s}$ and $0.6 \mathrm{MPa}$ were applied.

After pressing, the panels were stored at standard climate conditions for 2 weeks allowing for acclimatizing and to ensure sufficient curing.

In a further step, the samples of glued spruce lamellas with a length of $5 \mathrm{~mm}$, width of $2 \mathrm{~mm}$ and a thickness of $2 \mathrm{~mm}$ were cut from the adhesive bond region. By embedding the samples in a low-viscosity epoxy resin (Agar R 1078, Agar Science Ltd., Essex, GB) using vacuum, the cell lumen was entirely filled in order to stabilize the cells for the subsequent nanoindentation measurement. According to 
the literature (Frihart 2009), cell walls are typically not infiltrated by the epoxy resin by this simple impregnation process (no solvent exchange was performed). After being cured at $60{ }^{\circ} \mathrm{C}$, the single specimens got fixed by a two-component epoxy resin (UHU Plus Sofortfest, Bolton, Switzerland) to metal discs, and smooth surfaces were cut via ultra-microtome (Ultracut-R, Leica, Vienna, Austria) using diamond knifes (Histo, Diatome, Hatfield, Pennsylvania, USA).

Prior to mechanical testing, the samples were observed using incident light microscopy (Axioplan 2, Zeiss, Jena, Germany) to facilitate the selection of proper indentation positions. For each adhesive type, two specimens with a consistent adhesive polymer bond line, a distinct interphase region including cell lumen close to the pure adhesive polymer filled with adhesive, and a considerable amount of pure transition wood cells (with no adhesive contact) were selected (Fig. 1).

In a final step, the prepared samples were glued with a two-component epoxy resin to a metal disc with a diameter of $30 \mathrm{~mm}$ to enable a higher number of samples at the limited magnetic positions of the nanoindenter stage. The testing was conducted in an environmentally isolated and hydrothermally controllable atmosphere by conditioning the entire test chamber. A relative humidity (RH) generator (RH200 relative humidity generator, L\&C Science, Hialeah, Florida, USA) was used to establish a dry (28\% RH), moderate $(47 \% \mathrm{RH})$ and moist (approx. 66\% RH) moisture condition for the samples (Table 1). Here, the aim was to reach equilibrium moisture contents (EMCs) for spruce of approximately 6\%, 9\% and 12\% according to Keylwerth and Noack (1964). As a control, the dry climate condition was reestablished, and measurements were repeated (re-dry). To enable a better interpretation of the overall behaviour of adhesively bonded wood, the data gained in this study were combined with indentation data of creep measurements of the pure adhesive polymer acquired with similar methods and published in a previous work (Rindler et al. 2018). It needs to be mentioned that for the sake of clarity, the reduced elastic modulus data used for the present work were obtained from the creep measurement only and not combined from creep and relaxation as published in Rindler

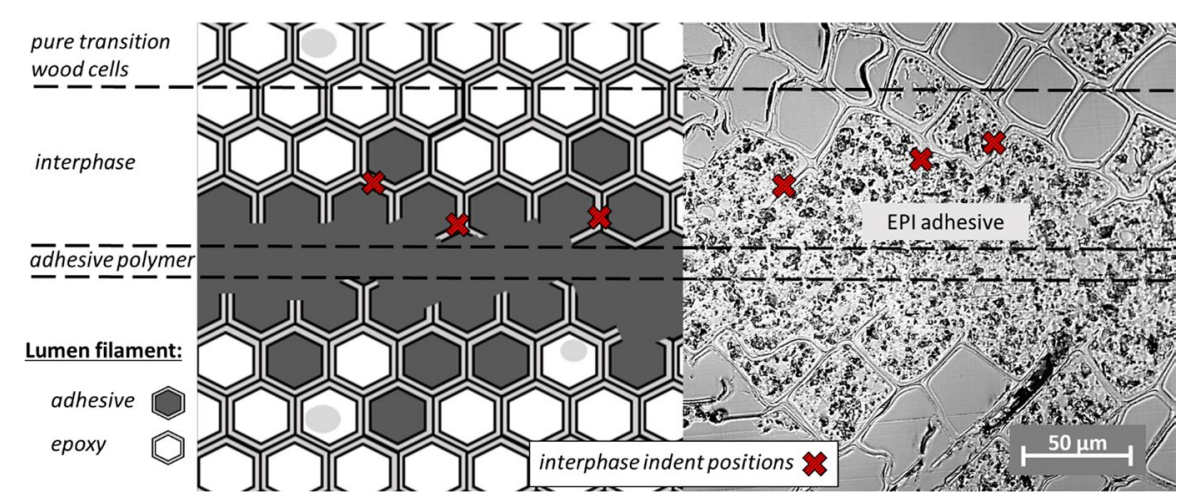

Fig. 1 Regions within a wood/adhesive bond with an example of indent positions. Schematic (left) and incident light microscopy image of emulsion polymer isocyanate (EPI) (right) adhesive polymer surface at $\times 200$ magnification 
Table 1 Measured temperature and relative humidity $(\mathrm{RH})$ in the test environment and classification into dry, moderate, moist and re-dry moisture conditions of the samples

\begin{tabular}{lllll}
\hline Run order & $\begin{array}{l}\text { Measured } \\
\text { temperature } \\
\left({ }^{\circ} \mathrm{C}\right)\end{array}$ & $\begin{array}{l}\text { Established RH for } \\
\text { wood cell walls (\%) }\end{array}$ & $\begin{array}{l}\text { Established RH for adhe- } \\
\text { sive testing (Rindler et al. } \\
2018)\end{array}$ & Classification \\
\hline 1 & 23.9 & 28.1 & $14.8 \%$ & Dry (<30\% RH) \\
2 & 24.8 & 47.3 & $42.9 \%$ & $\begin{array}{c}\text { Moderate (approx. } 45 \% \\
\text { RH) }\end{array}$ \\
3 & 24.4 & 66.7 & $66.0 \%$ & Moist $(>66 \%$ RH) \\
4 & 24.0 & 28.2 & $\mathrm{x}$ & Re-dry $(<30 \% \mathrm{RH})$ \\
\hline
\end{tabular}

et al. (2018). In the study cited, the established RH were $14.8 \%, 42.9 \%$ and $66.0 \%$ with the aim to reach EMC values of approximately $4 \%, 8 \%$ and $12 \%$ for spruce wood according to Keylwerth and Noack (1964). Combining the data of the present and the previous study, a more general condition classification was used, namely dry for $\mathrm{RH}<30 \%$, moderate for around $45 \% \mathrm{RH}$ and moist for $>66 \% \mathrm{RH}$ (Table 1). All samples were exposed to the specific climate conditions for at least $6 \mathrm{~h}$ before the indentation test was started, to ensure a proper acclimatizing.

\section{Nanoindentation}

A Hysitron TriboIndenter (Hysitron Inc., Minneapolis, USA, www.hysitron.com) with a three-sided diamond indenter tip (Berkovich type) was used for the present study. For the case of cell wall indents, topography scans of the sample surfaces with a size of $10 \times 10 \mu \mathrm{m}^{2}$ were generated via tip imaging before and after every indent to ensure and control a proper positioning of the tip within the S2 cell wall layer for mechanical measurements (Fig. 2). To avoid edge effects (Jakes et al. 2009), a minimum cell wall thickness of $2.1 \mu \mathrm{m}$ for the S2 was chosen for the tests (approx. $0.7 \mu \mathrm{m}$ indent diameter). The presence of adhesive is more frequently observed in earlywood than in latewood tissue due to bigger lumen dimensions and consequently

Fig. 2 Topography scan of spruce/EPI interphase cell walls with three remaining indents $(0,1,2)$ within $\mathrm{S} 2$ cell wall layers after testing with $100 \mu \mathrm{N}$ maximum load

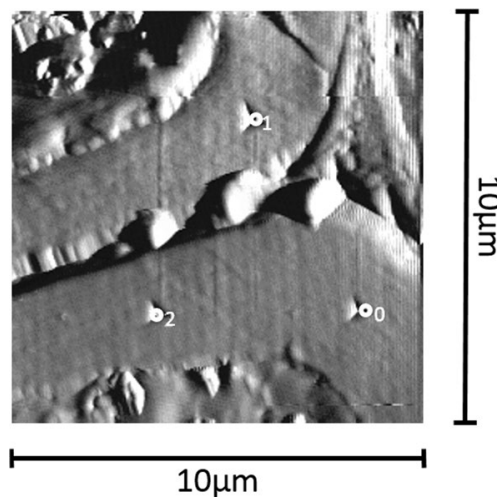


higher permeability. However, spruce earlywood cell wall thickness usually is below $2 \mu \mathrm{m}$ and more difficult to test as a consequence. Thus, mainly transition wood cells were used for the indentation measurements as lumen penetration is still observable, while cell wall thickness allows for proper nanoindentation measurement. All findings of the nanoindentation measurement were analysed statistically using a singlefactor variance analysis (ANOVA; 95\% confidence interval) with a post hoc Scheffé test to compare the means between comparable groups.

The indentation measurements were taken in load-controlled mode with $0.1 \mu \mathrm{N}$ preload. A three-segment load ramp with a maximum load of $100 \mu \mathrm{N}$ was established (Fig. 3). The maximum load was built up in $3 \mathrm{~s}$, maintained for $60 \mathrm{~s}$ to monitor viscoelastic creep and released in $3 \mathrm{~s}$.

The resulting maximum indentation depths were ranged from 70 to $100 \mathrm{~nm}$ at an applied maximum force of $100 \mu \mathrm{N}$ for all sample types. For each adhesive sample, a minimum of 12 indents were conducted at interphase regions and pure wood cells, respectively, resulting in a total number of 96 indents per climatic condition. The reduced elastic modulus, hardness $\left(P_{\max }\right.$ divided by the contact area $A$ at $\left.P_{\max }\right)$ and indentation creep were obtained from the load-depth curves, following the wellestablished and described procedure for NI data evaluation (CSM-Instruments 2002; Oliver and Pharr 1992; Stöckel et al. 2013). The data described in Rindler et al. (2018) were acquired following the identical procedure but with a different holding time of $120 \mathrm{~s}$ (instead of $60 \mathrm{~s}$ ) for creep and a maximum load of $500 \mu \mathrm{N}$ (instead of $100 \mu \mathrm{N})$.

Therefore, no quantitative comparison of the absolute creep values measured in cells and adhesives was done in the following.

\section{Results and discussion}

The reduced elastic modulus $E_{\mathrm{r}}$ of the pure wood cells, the adhesive polymer present in the bond line and the interphase cells surrounded by adhesive are displayed in Fig. 4 for different humidity levels.

As expected, all wood and interphase cell walls present in a wood/adhesive bond show, with around $20 \mathrm{GPa}$, a clearly higher reduced elastic modulus compared to the adhesive polymer, the latter ranging from 2 to $11 \mathrm{GPa}$ (median).

Fig. 3 Load-depth curve a with segments indicating loading (1), holding (2) and unloading (3). Corresponding depth-time curve $\mathbf{b}$ for nanoindentation measurements with the initial depth (h1) after loading time (t1) where the maximum load is built up and the resulting depth (h2) after holding time (t2)

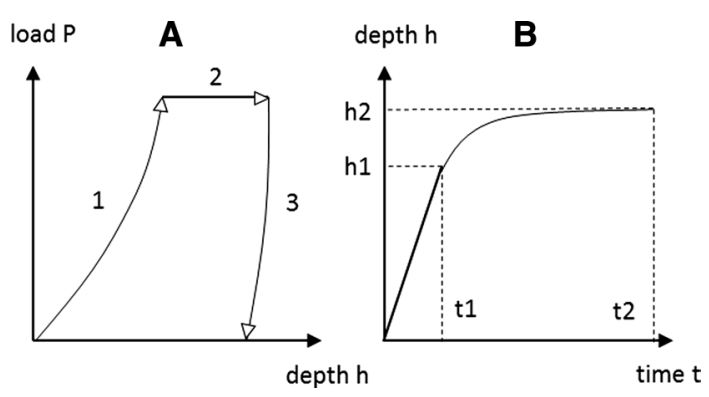



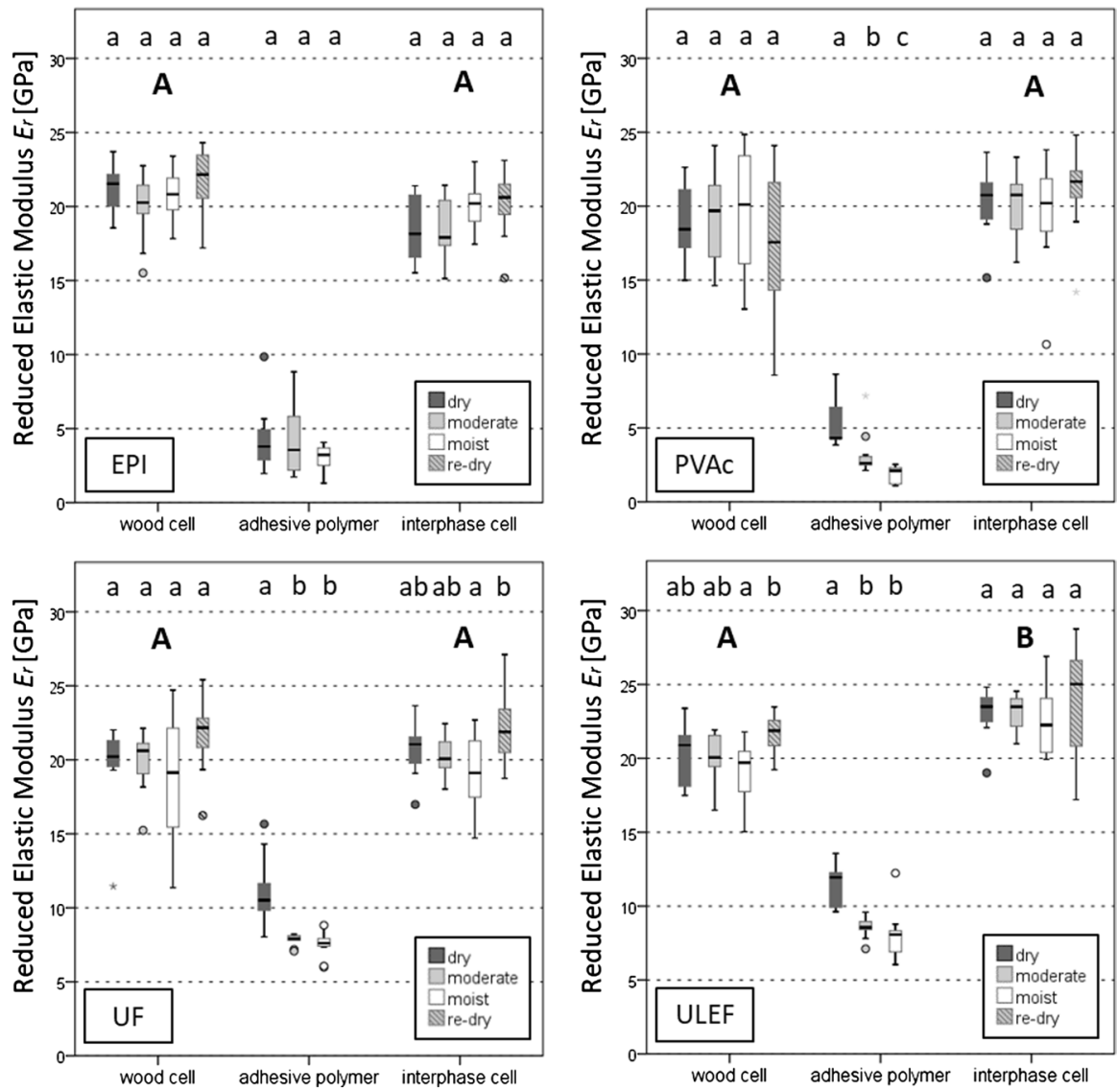

Fig. 4 Moisture-dependent reduced elastic modulus of the pure adhesive polymer, S2 cell walls of wood/ adhesive interphase region and of wood cells distant from the bond; specimens glued with emulsion polymer isocyanate (EPI), polyvinyl acetate (PVAc), urea formaldehyde (UF) and ultra-low formaldehyde-emitting amino resin (ULEF). ANOVA $(p \leq 0.05)$ indicates statistically significant differences in $E_{\mathrm{r}}$ within the group $(a \neq b, a b=a, a b=b)$ or between groups $(A \neq B)$ if letters are different. Box and whisker plots indicate median, $25 \%$ and $75 \%$ percentile, maximum and minimum values, which are not outliers, considered outliers (dots) and neglected outsiders (asterisk)

In three cases (EPI, UF and ULEF) out of four, the pure wood cells reveal a slight but systematic decrease in the reduced elastic moduli with increasing relative humidity. Due to the considerable scattering of the values, no statistically significant differences within the groups with changing climate conditions could be observed for the investigated moisture range. A comparison of dry and re-dry climate state of the wood cells and the interphase cells tends to show higher $E_{\mathrm{r}}$ values for almost all adhesive types in re-dry climate state. However, the statistical evaluation revealed no significant difference between the original and the re-established dry climate for any adhesive type. However, there are differences for UF in the interphase cells and ULEF wood cells between the moist and re-dry state. 
For the cured adhesive polymers, the pre-polymerized adhesives (EPI and PVAc) perform below $5 \mathrm{GPa}$. The thermoplastic PVAc is significantly affected by moisture, reducing its dry $E_{\mathrm{r}}$ by approx. $50 \%$ when tested in moist conditions. EPI showed only a slight decrease in $E_{\mathrm{r}}$ (not significant) with increasing ambient humidity. Thus, EPI clearly offers the most stable elastic properties compared to all other tested adhesives.

Thermosetting UF and ULEF show a similar behaviour regarding $E_{\mathrm{r}}$ at moderate climatic conditions with values between 8 and $9 \mathrm{GPa}$. $E_{\mathrm{r}}$ significantly increases in dry ambient climate condition to $12 \mathrm{GPa}$ and shows a tendency to decrease in moist state. A more detailed description of the adhesive polymer results can be found in Rindler et al. (2018).

Regarding the interphase cell walls, the trend of decreasing modulus with increasing moisture is still evident for ULEF and UF interphase cell walls. A systematic trend is again not visible for EPI, although the values in dry and moist states are significantly different from the moderate state. PVAc interphase cells are characterized by a high degree of scattering; therefore, a systematic change cannot be derived from the data. Similar to the pure wood cells, the influence of moisture on wood/ adhesive interphase cells is statistically significant only in a few cases, namely UF between moist and dry.

Comparing between the pure wood cells and the interphase cells, only the interphase of the ULEF adhesive shows systematically (significant) higher $E_{\mathrm{r}}$ compared to the pure wood cells, indicating penetration of adhesive compounds into the cell wall. For the other adhesives, no mechanical effect as a result of cell wall penetration is visible. However, a possible penetration of adhesive components cannot be excluded (e.g. for the case of UF), but an effect on mechanical properties of the cells is not visible.

The results for indentation hardness $H$ for the pure wood cells, the pure adhesive polymer and the wood/adhesive interphase cells, as shown in Fig. 5, display the remarkable differences between the adhesive systems.

The pure wood cells show hardness values of around $0.5 \mathrm{GPa}$. Similar to the reduced elastic modulus, a tendency of decreasing hardness with increasing humidity can be observed for the wood cell walls of ULEF samples, while this trend is not visible for EPI, PVAc and UF samples.

The comparison between the dry and re-dry climate states for hardness of the pure wood cell and the interphase revealed no significant difference although again higher values for the re-established state are observable.

Here, it has to be mentioned that although dry and re-dry do not differ, there is a significant difference between the re-dry and the moderate and the re-dry and the moist states for UF and ULEF for the wood cells and the interphase cells. However, there is no statistical difference for the dry state of run order one.

Hardness of the pure adhesive polymers is again dramatically lower for prepolymerized EPI and PVAc adhesive polymers compared to both the thermosetting adhesive polymers as well as wood cells. Another time, PVAc changes its properties significantly with increasing moisture, while EPI remains comparably constant.

The amino resins (UF and ULEF) show similar hardness values compared to pure wood cells, both with values between 0.4 and $0.6 \mathrm{GPa}$. Noticeable is the 

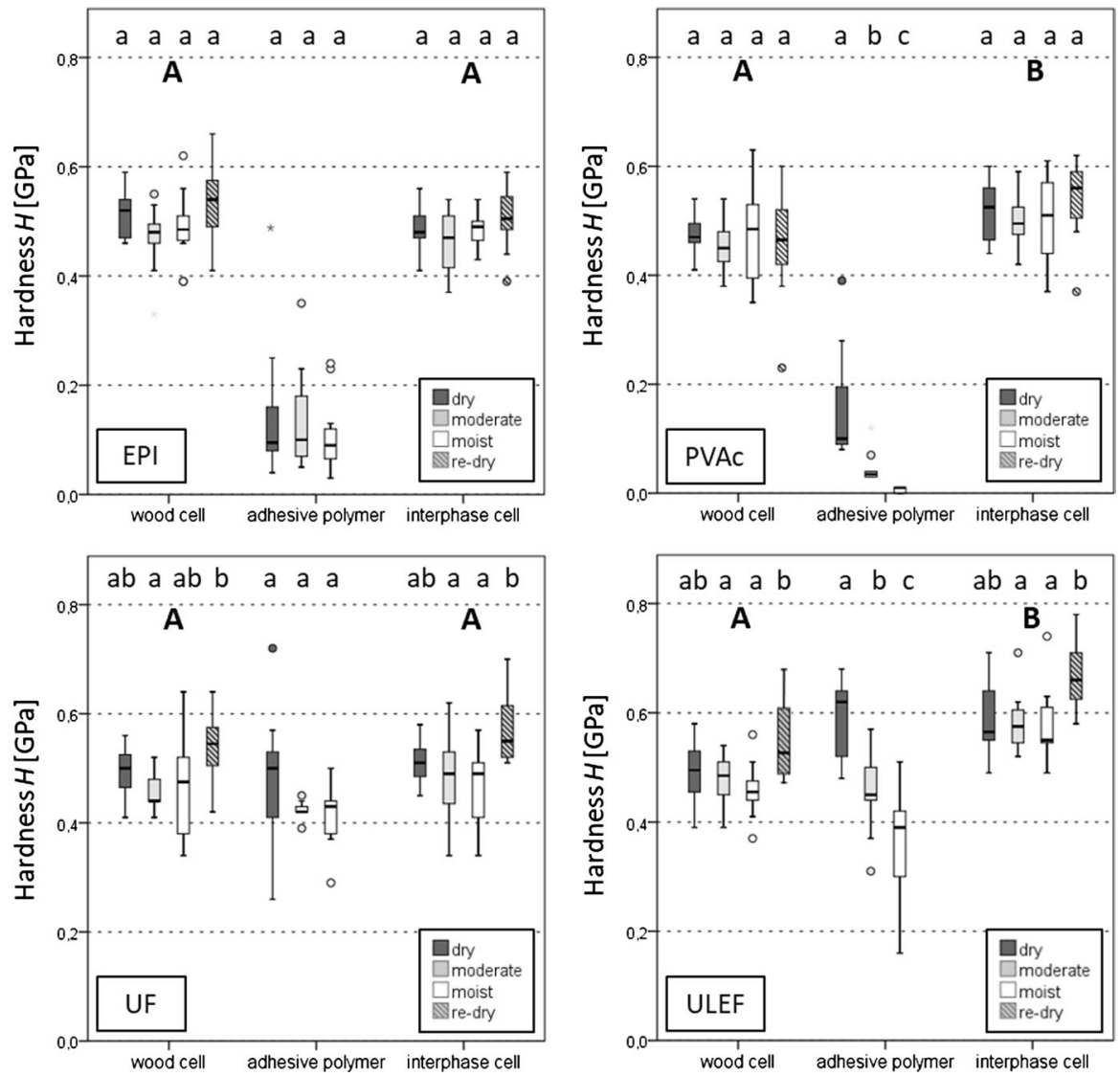

Fig. 5 Moisture-dependent hardness of the pure adhesive polymer, S2 cell walls of wood/adhesive interphase region and of wood cells distant from the bond; specimens glued with emulsion polymer isocyanate (EPI), polyvinyl acetate (PVAc), urea formaldehyde (UF) and ultra-low formaldehyde-emitting amino resin (ULEF). ANOVA $(p \leq 0.05)$ indicates statistically significant differences in $H$ within the group $(a \neq b, a b=a, a b=b)$ or between groups $(A \neq B)$ if letters are different. Box and whisker plots indicate median, $25 \%$ and $75 \%$ percentile, maximum and minimum values, which are not outliers, considered outliers (dots) and neglected outsiders (asterisk)

dramatic change in hardness for the ULEF adhesive, while this change is less pronounced for UF. The statistical evaluation between the moisture states of the pure adhesive polymers only reveals significant differences for ULEF and PVAc; for ULEF, all moisture levels showed significant differences to each other. With by far the lowest hardness values compared to the other adhesives, PVAc shows a significant difference between dry to moderate and moist, but there is no significant difference between the moderate and the moist climate states. No significant difference can be observed between the different moisture levels for EPI and UF. Despite the statistical significance, all pure adhesive polymers decrease hardness when the surrounding relative humidity is increasing. 
Values for hardness of the wood/adhesive interphase cells show comparably similar values to pure wood cells in a range of around $0.5 \mathrm{GPa}$. Again, the results show no statistically significant differences between the comparable moisture levels of interphase and pure wood for EPI and UF.

Interestingly, EPI and PVAc reveal only little changes of hardness due to moisture compared to UF and ULEF interphase cells.

Comparing between the groups, in general, no big differences between the interphase and the pure wood are visible for EPI and UF. PVAc shows higher values for the interphase with significant differences for the dry and the moderate
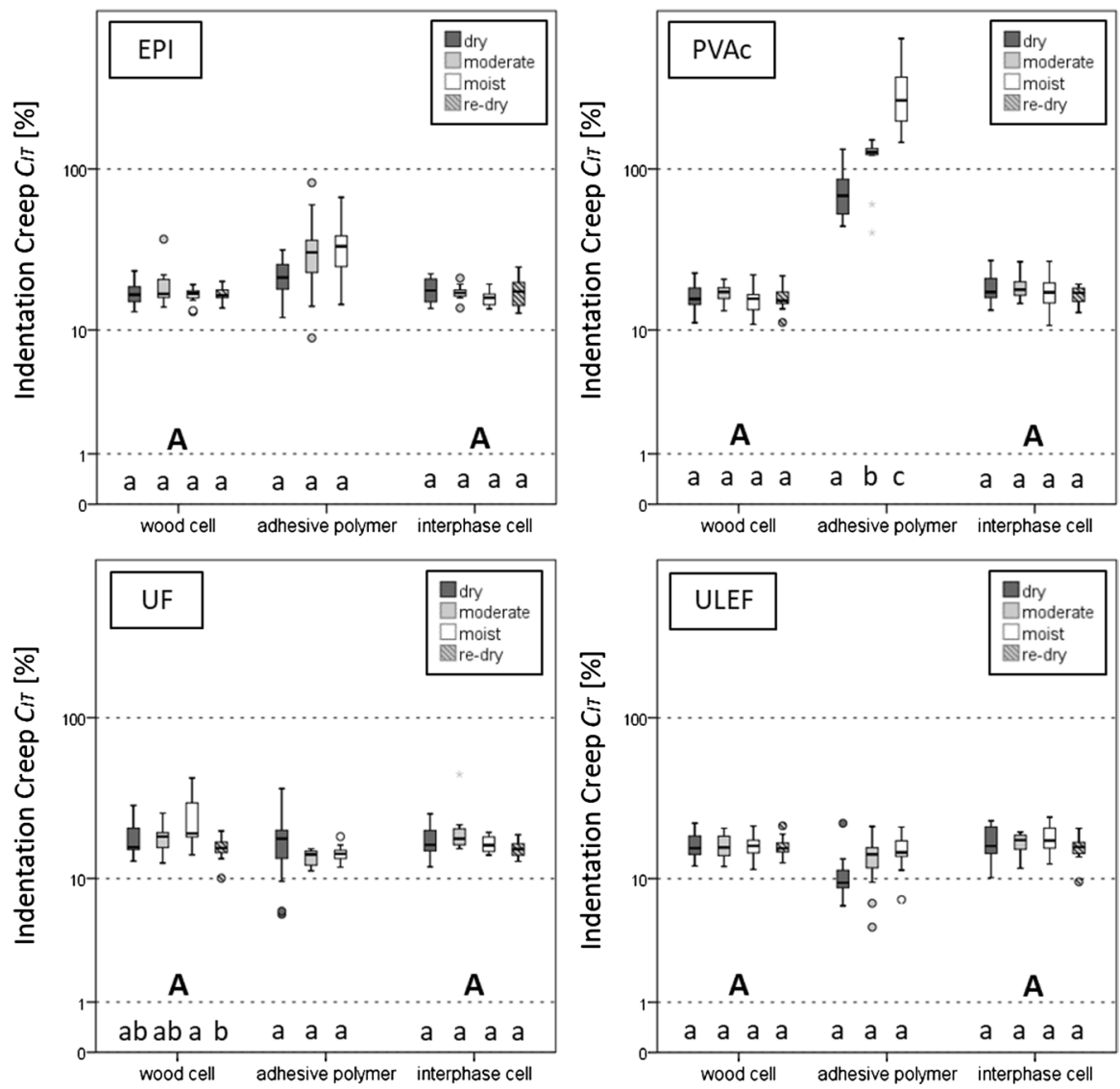

Fig. 6 Moisture-dependent indentation creep of the pure adhesive polymer, S2 cell walls of wood/adhesive interphase region and of wood cells distant from the bond; specimens glued with emulsion polymer isocyanate (EPI), polyvinyl acetate (PVAc), urea formaldehyde (UF) and ultra-low formaldehyde-emitting amino resin (ULEF). ANOVA $(p \leq 0.05)$ indicates statistically significant differences in $C_{I T}$ within the group $(\mathrm{a} \neq \mathrm{b}, \mathrm{ab}=\mathrm{a}, \mathrm{ab}=\mathrm{b})$ or between groups $(\mathrm{A} \neq \mathrm{B})$ if letters are different. Box and whisker plots indicate median, $25 \%$ and $75 \%$ percentile, maximum and minimum values, which are not outliers, considered outliers (dots) and neglected outsiders (asterisk) 
states only. The ULEF adhesive bond shows significantly higher values than the pure wood cell of approx. 0.6 GPa.

As visible in Fig. 6, the results for moisture-dependent indentation creep $C_{\mathrm{IT}}$ display the viscoelastic variability of the individual regions within the different adhesive bonds.

The creep behaviour of pure wood cells seems to be relatively unaffected by moisture within the observed humidity range with values of around 15-20\%. Beside no statistical differences between the different moisture levels, three out of four samples show no specific tendency of the creep change for the established humidity levels. Only for the UF pure wood cell samples, a slight creep increase with increasing ambient humidity is visible. Again, the original and the re-established dry climate of the pure wood cells and the interphase cells revealed no significant difference between the dry and re-dry climate for any adhesive type. Only for UF between the moist and re-dry state, a significant difference for the wood cells could be observed.

Compared to the wood cells, the pure adhesive polymers show stronger effects caused by changed environment. As properly described in a previous study (Rindler et al. 2018), PVAc is the most sensitive adhesive of the tested group to moisture, showing statistically significant differences between the moisture states for the indentation creep almost doubling (dry to moderate) and tripling (dry to moist) its creep factor.

In contrast, EPI, UF and ULEF reach comparable viscoelastic creep levels. With values between 20 and $30 \%$, the EPI adhesive shows no statistically significant difference between the different moisture states, although a tendency for higher creep values with increasing $\mathrm{RH}$ is visible.

The in situ polymerized adhesives (UF and ULEF) demonstrate, as previously described (Rindler et al. 2018), lowest creep among the tested adhesive systems (10-20\%). Only the ULEF displays significant differences between dry and moist states.

The creep values achieved for the interphase regions do not significantly differ to the ones of pure wood cells.

The ULEF shows a tendency of less creep in the dry climate state compared to wood. Concerning the moisture levels, no significant difference can be identified between the moderate and moist states, but between them and the dry climate state.

Regarding the creep differences between the pure adhesive polymers and the pure wood and/or interphase cell walls, it has to be mentioned that the indentation holding times for creep measurement for the pure adhesive polymers and the interphase/ pure wood cells are different (60 versus $120 \mathrm{~s}$ ). Due to this, a quantitative comparison of the absolute values measured in cells and adhesives is not meaningful, but differences by trend are described in the following.

As expected, the pre-polymerized adhesives (EPI and PVAc) tend to increase their creep with increasing moisture, whereas the in situ polymerized adhesives (UF and ULEF) and the wood properties tend to remain constant.

For the pure wood cells, a quite similar average of $0.5 \mathrm{GPa}$ was observed for the hardness, what is in the range of values found for a variety of different climate conditions applied in the literature (Wagner et al. 2015), but higher as observed for transition wood cells at moderate climate conditions elsewhere (Gindl and Gupta 2002; 
Konnerth and Gindl 2006). The reduced elastic modulus with values of around $20 \mathrm{GPa}$ and the indentation creep with values between 15 and $20 \%$ remained quite constant with changing surrounding climate and are reflecting values of the literature (Wagner et al. 2015) for pure wood cells.

A very detailed discussion on the moisture-related mechanical findings of the reduced elastic modulus and creep of the pure adhesive polymers can be found elsewhere (Rindler et al. 2018) and is not repeated here.

In general, the mechanical behaviour of all tested pure adhesive polymers is well in line with findings summarized in the literature (Stöckel et al. 2010, 2013), although the $H$ values for UF and ULEF in the recent study are lower.

Most of the mechanical values of interphase and pure wood revealed no statistically significant differences. This is considered as an indicator that the $\mathrm{S} 2$ cell wall was mechanically not affected by most of the tested adhesives, only by ULEF.

The ULEF adhesive showed relevant differences between the interphase and the pure wood cell wall for the hardness and the reduced elastic modulus. According to the literature (Frihart 2009) and the findings of the present and other studies (Gindl et al. 2002, 2003; Herzele et al. 2018; Stöckel et al. 2010), it can be assumed that at least some compounds of the ULEF resin infiltrated the S2 cell wall. This assumption is made without performing any additional tests of its molecular weight. The values of the hardness are in a similar range (Herzele et al. 2018), or slightly lower (Stöckel et al. 2010) compared to literature values. Values for the reduced elastic modulus are slightly higher than results obtained earlier (Herzele et al. 2018) using a different indenter geometry $\left(60^{\circ}\right.$ conical tip), but perfectly match with studies using the same Berkovich-type indenter (Stöckel et al. 2010) at moderate climate conditions. Testing anisotropic materials such as wood cell walls with different indenter opening angles are known to bias measured $E_{\mathrm{r}}$ results (Konnerth et al. 2009), but this should not affect measurements on isotropic materials such as adhesive polymers.

Although findings from the literature gave reason to believe that UF resins also are capable of infiltrating the cell wall and modifying its mechanical properties (Gindl and Gupta 2002; Stöckel et al. 2010), values for UF did not indicate any mechanically detectable change of interphase cell walls compared to pure wood cell walls in the present study. This could be either a result of missing penetration into the cell wall, a non-uniform infiltration pattern (Paris and Kamke 2015) and missing the infiltrated region or simply a lack of mechanically detectable differences. Since the amino resins used in the recent study are especially designed for solid wood application, their viscosity ( $>2000 \mathrm{mPa}$ s) is higher compared to resins typically used for other products like particleboards (approx. $400 \mathrm{mPa} \mathrm{s}$ ). This is suspected to also affect the penetration behaviour of the adhesive (Dunky and Niemz 2013). Reference studies on UF cell wall penetration (Stöckel et al. 2010) were conducted, for example, on beech wood (Fagus sylvatica) that is known to have a higher permeability $\left(9.87 \times 10^{-16} \mathrm{~m}^{2}\right)$ compared to spruce wood (P. abies) $\left(9.87 \times 10^{-14} \mathrm{~m}^{2}\right)$ used in the present study (Siau 2012). Furthermore, the molecular weight distribution of the used UF resin is not known, which is decisive for cell wall penetration capability (Frihart 2009) as described in introduction.

The reason why ULEF shows cell wall modification, while UF does not show a similar effect remains unclear, but as the detailed formulation of the adhesives used 
in this study is not known, no further interpretation on this specific result can be done here.

Similar to the UF, the EPI also showed neither a significant difference, nor a trend between the wood cell and the interphase cell. Although the isocyanate component of EPI may react with wood (Frihart and Wescott 2008; Grøstad and Pedersen 2010), the recent findings based on mechanical properties indicate no cell wall modification and therefore support assumptions from the literature that no diffusion into the cell wall occurs with EPI (Frihart and Wescott 2008) components.

The most surprising results were obtained for the hardness of the PVAc with statistically significant differences between pure wood cell and interphase. The hardness obtained from the peak load $\left(P_{\max }\right)$ primarily considers plastic deformation of the sample and is, contrary to the elastic modulus, fibre-independent (microfibril angle) (Gindl et al. 2004; Jäger et al. 2011; Jakes et al. 2015). Comparing the differences of the mean hardness values between the pure wood cells and the interphase cells of PVAc (dry 0.04 GPa, moderate $0.05 \mathrm{GPa}$, moist $0.03 \mathrm{GPa}$ ) and ULEF (dry $0.1 \mathrm{GPa}$, moderate $0.1 \mathrm{GPa}$, moist $0.11 \mathrm{GPa}$ ), it becomes clear that the differences between the means are of a different magnitude for ULEF and PVAc. Considering the maximum values for the mean differences between wood and interphase of the other adhesives (EPI $0.03 \mathrm{GPa}$, UF $0.02 \mathrm{GPa}$ ), PVAc values are closer to the non-significant group than to ULEF. Further, ULEF shows significant differences between wood cell and interphase cell; PVAc does not. As the size of PVAc prepolymers should not allow for penetrating nor modifying the S2 cell wall (Frihart 2009), the origin of this difference remains unclear.

The here neglected MFA and lignin content of the selected S2 cell walls could also be the reason, why only in a few cases statistically significant differences in the reduced elastic modulus between dry and moist climatic conditions could be observed for spruce wood in the present study.

Although there is no significant material degradation due to the temporary exposure to higher moisture contents, interestingly a trend of non-significant increase in modulus and the hardness is identifiable between the dry and re-dry states of run orders 1 and 4. Again, hardness is more sensitive and especially UF and ULEF follow the described trend more explicitly, but for the pure wood cell and the interphase cell. This might be an indicator that during the experiment not exactly the same dry moisture content could be reached, which might be caused by minimal irregularities in the acclimatizing durations.

Although the contribution of the individual bond line regions to the macroscopic performance of a bond is not further analysed in the present study, it can be said that the recent findings confirm and support the statements from the literature that prepolymerized and in situ polymerized adhesives will differently respond to occurring stresses (Frihart 2009; Frihart and Wescott 2008) due to significant differences in elastic and viscoelastic behaviour.

In general, all tested adhesives, apart from EPI, show a higher sensitivity to climate conditions representing a typical range occurring in interior applications, compared to wood.

Wood shows a significantly higher reduced modulus $E_{\mathrm{r}}$ than all tested adhesives. In contrast, moisture-related hardness $H$ of UF and ULEF was very similar in 
magnitude to the one of the natural material wood. Only for the viscoelastic behaviour, higher values were observed for EPI and PVAc, UF and ULEF again showed similar or a lower tendency to creep (ULEF in dry climate state) compared to wood.

Although the reduced elastic modulus and the hardness of ULEF samples indicate a penetration of the cell wall, no influence on the creep behaviour of the interphase cells could be detected.

\section{Conclusion}

Nanoindentation once again showed to be a valuable tool to gain detailed mechanical information on the individual regions of an adhesive bond at the microscale level. This time, the influence of air humidity on selected elastic, plastic and viscoelastic properties of the main regions present in an adhesive bond, i.e. the adhesive, wood and interphase cell walls, was investigated. The data gained provide a more detailed insight into differences inherent to various adhesive systems used in wood industry.

The findings of the present investigation demonstrate mechanical differences, in particular for the reduced elastic modulus, between cure adhesives and pure wood cells. Mechanical properties of the tested wood cell walls seem to be less affected by moisture changes than the used adhesives. This could be based on the local microfibril orientation of the observed spruce cell walls. Pure adhesive polymers show a tendency to decrease their modulus and hardness when the ambient relative humidity is increased for PVAc, UF and ULEF, while both parameters remained comparably stable for an EPI adhesive. Concerning creep, EPI and PVAc show an increasing creep rate, while UF and ULEF remained rather stable with increasing relative humidity. The wood cell walls did not show a detectable change in creep properties as a result of changed humidity conditions.

For the selected adhesives, only ULEF showed evidence of cell wall penetration based on mechanical observations.

Acknowledgements Open access funding provided by University of Natural Resources and Life Sciences Vienna (BOKU). The authors are thankful for financial support for the project "Wood: next generation materials and processes - from fundamentals to implementations", funded by the Austrian Research Promotion Agency (FFG) (Project No.: 844.608). The authors acknowledge the technical support for the nanoindenter equipment of Olaf Lahayne from the Institute for Mechanics of Materials and Structures, Faculty of Civil Engineering, University of Technology Vienna.

Open Access This article is distributed under the terms of the Creative Commons Attribution 4.0 International License (http://creativecommons.org/licenses/by/4.0/), which permits unrestricted use, distribution, and reproduction in any medium, provided you give appropriate credit to the original author(s) and the source, provide a link to the Creative Commons license, and indicate if changes were made. 


\section{References}

Brockmann W, Geiß PL, Klingen J, Schröder KB (2008) Adhesive bonding: materials, applications and technology. Wiley, Weinheim

CSM Instruments (2002) Overview of mechanical testing standards. Advanced mechanical surface testing, Appl. Bull 18, Peseux

Dunky M, Niemz P (2013) Holzwerkstoffe und Leime: Technologie und Einflussfaktoren (Wood-based panels and glues: technology and influencing factors). Springer, Berlin. https://doi.org/10.1007/9783-642-55938-9

Eckmann R (2007) Charakterisierung der Adhäsiven, Kohäsiven und mechanischen Eigenschaften der Klebfuge in einer Holzverklebung. (Characterisation of adhesive, cohesive and mechanical properties in the glue line of wood bondings). Dissertation, University of Natural Resources and Life Science Vienna

Frihart CR (2004)Adhesive interactions with wood. In: Fundamentals of composite processing: proceedings of a workshop, 5-6 Nov 2003. Madison, WI, US Department of Agriculture, Forest Service, Forest Products Laboratory, 2004. General technical report FPL; FPL-GTR-149, pp 29-38

Frihart CR (2009) Adhesive groups and how they relate to the durability of bonded wood. J Adhes Sci Technol 23:601-617. https://doi.org/10.1163/156856108X379137

Frihart CR, Wescott JM (2008) Why do some wood-adhesive bonds respond poorly to accelerated moisture-resistant tests? In: 9th Pacific rim bio-based composites symposium: innovation and challenges in bio-based composites-How far to the New Frontier?: 5th-8th Nov 2008, Rotorua, New Zealand, pp 51-58

Gindl W, Gupta H (2002) Cell-wall hardness and Young's modulus of melamine-modified spruce wood by nano-indentation. Compos A Appl Sci Manuf 33:1141-1145

Gindl W, Schöberl T (2004) The significance of the elastic modulus of wood cell walls obtained from nanoindentation measurements. Compos A Appl Sci Manuf 35:1345-1349. https://doi. org/10.1016/j.compositesa.2004.04.002

Gindl W, Dessipri E, Wimmer R (2002) Using UV-microscopy to study diffusion of melamine-urea-formaldehyde resin in cell walls of spruce wood. Holzforschung 56:103-107

Gindl W, Zargar-Yaghubi F, Wimmer R (2003) Impregnation of softwood cell walls with melamine-formaldehyde resin. Biores Technol 87:325-330

Gindl W, Gupta HS, Schöberl T, Lichtenegger HC, Fratzl P (2004) Mechanical properties of spruce wood cell walls by nanoindentation. Appl Phys A 79:2069-2073. https://doi.org/10.1007/s0033 9-004-2864-y

Gindl W, Sretenovic A, Vincenti A, Muller U (2005) Direct measurement of strain distribution along a wood bond line, part 2: effects of adhesive penetration on strain distribution. Holzforschung 59:307-310

Grøstad K, Pedersen A (2010) Emulsion polymer isocyanates as wood adhesive: a review. J Adhes Sci Technol 24:1357-1381. https://doi.org/10.1163/016942410x500981

Habenicht G (2002) Kleben: gundlagen, technologien, anwendung (adhesive bonding: principles, technologies, application). Springer, Berlin

Hass P, Wittel FK, Mendoza M, Herrmann HJ, Niemz P (2012) Adhesive penetration in beech wood: experiments. Wood Sci Technol 46:243-256. https://doi.org/10.1007/s00226-011-0410-6

Herzele S, van Herwijnen HWG, Edler M, Gindl-Altmutter W, Konnerth J (2018) Cell-layer dependent adhesion differences in wood bonds. Compos A Appl Sci Manuf 114:21-29. https://doi. org/10.1016/j.compositesa.2018.07.037

Jäger A, Bader TK, Hofstetter K, Eberhardsteiner J (2011) The relation between indentation modulus, microfibril angle, and elastic properties of wood cell walls composites part A. Appl Sci Manuf 42:677-685

Jakes JE, Frihart CR, Beecher JF et al (2009) Nanoindentation near the edge. J Mater Res 24:1016-1031. https://doi.org/10.1557/JMR.2009.0076

Jakes JE et al (2015) Synchrotron-based X-ray fluorescence microscopy in conjunction with nanoindentation to study molecular-scale interactions of phenol-formaldehyde in wood cell walls. ACS Appl Mater Interfaces 7:6584-6589

Kamke FA, Lee JN (2007) Adhesive penetration in wood-a review. Wood Fiber Sci 39:205-220

Keylwerth R, Noack D (1964) Die Kammertrocknung von Schnittholz (Chamber drying of sawn wood). Holz Roh Werkst 22:29-36 
Konnerth J, Gindl W (2006) Mechanical characterisation of wood-adhesive interphase cell walls by nanoindentation. Holzforschung 60:429-433. https://doi.org/10.1515/hf.2006.067

Konnerth J, Gindl W (2008) Observation of the influence of temperature on the mechanical properties of wood adhesives by nanoindentation. Holzforschung 62:714-717. https://doi.org/10.1515/ hf. 2008.108

Konnerth J, Harper D, Lee SH, Rials TG, Gindl W (2008) Adhesive penetration of wood cell walls investigated by scanning thermal microscopy (SThM). Holzforschung 62:91-98. https://doi.org/10.1515/ HF.2008.014

Konnerth J, Gierlinger N, Keckes J, Gindl W (2009) Actual versus apparent within cell wall variability of nanoindentation results from wood cell walls related to cellulose microfibril angle. J Mater Sci 44:4399-4406. https://doi.org/10.1007/s10853-009-3665-7

Marra AA (1992) Technology of wood bonding, principles in practice, 1st edn. Van Nostrand Reinhold, New York

McKinley P, Kamke FA, Sinha A, DA V, Jakes JE (2018) Analysis of adhesive penetration into wood using nano-X-ray computed tomography. Wood Fiber Sci 50:66-76

Modzel G, Kamke FA, De Carlo F (2011) Comparative analysis of a wood: adhesive bondline. Wood Sci Technol 45:147-158

Müller U, Gindl W, Teischinger A (2005) Berührungslose Dehnungsmessung in Holz- und Holzwerkstoffen mittels Elektronischer Laser Speckle Interferometrie (Contact-free strain measurement in wood and derived timber products using electronic laser speckle interferometry). Holztechnologie 46:48-49

Obersriebnig M, Veigel S, Gindl-Altmutter W, Konnerth J (2012) Determination of adhesive energy at the wood cell-wall/UF interface by nanoindentation (NI). Holzforschung 66:781-787. https://doi. org/10.1515/hf-2011-0205

Oliver WC, Pharr GM (1992) An improved technique for determining hardness and elastic modulus using load and displacement sensing indentation experiments. Mater Res Soc 7:1564-1583

Paris JL, Kamke FA (2015) Quantitative wood-adhesive penetration with X-ray computed tomography. Int J Adhes Adhes 61:71-80

Paris JL, Kamke FA, Mbachu R, Gibson SK (2014) Phenol formaldehyde adhesives formulated for advanced X-ray imaging in wood-composite bondlines. J Mater Sci 49:580-591

Rapp AO, Bestgen H, Adam W, Peek RD (1999) Electron energy loss spectroscopy (EELS) for quantification of cell-wall penetration of a melamine resin. Holzforschung 53:111-117

Rapp AO, Sudhoff B, Pittich D (2011) Schäden an Holzfußböden vol 2 (Damage to wooden floors vol 2). Fraunhofer-IRB-Verlag, Stuttgart

Rindler A, Pöll C, Hansmann C, Müller U, Konnerth J (2018) Moisture related elastic and viscoelastic behaviour of wood adhesives by means of in situ nanoindentation. Int J Adhes Adhes 85:123-129. https://doi.org/10.1016/j.ijadhadh.2018.06.004

Serrano E, Enquist B (2005) Contact-free measurement and non-linear finite element analyses of strain distribution along wood adhesive bonds. Holzforschung 59:641-646. https://doi.org/10.1515/ hf.2005.103

Siau JF (2012) Transport processes in wood, vol 2. Springer, Heidelberg. https://doi.org/10.1007/978-3642-69213-0

Stöckel F, Konnerth J, Kantner W, Moser J, Gindl W (2010) Tensile shear strength of UF- and MUFbonded veneer related to data of adhesives and cell walls measured by nanoindentation. Holzforschung 64:337-342. https://doi.org/10.1515/hf.2010.046

Stöckel F, Konnerth J, Gindl-Altmutter W (2013) Mechanical properties of adhesives for bonding wood-a review. Int J Adhes Adhes 45:32-41. https://doi.org/10.1016/j.ijadhadh.2013.03.013

Suchsland O (1958) On the penetration of gluing and the significance of the penetration depth for the strength of glue joints. Holz Roh Werkst 16:101-108

Wagner L, Bos C, Bader TK, de Borst K (2015) Effect of water on the mechanical properties of wood cell walls-results of a nanoindentation study. BioResources 10:4011-4025

Wimmer R, Lucas BN, Oliver WC, Tsui TY (1997) Longitudinal hardness and Young's modulus of spruce tracheid secondary walls using nanoindentation technique. Wood Sci Technol 31:131-141

Wimmer R, Kläusler O, Niemz P (2013) Water sorption mechanisms of commercial wood adhesive films. Wood Sci Technol 47:763-775. https://doi.org/10.1007/s00226-013-0538-7

Xing C, Riedl B, Cloutier A (2004) Measurement of urea-formaldehyde resin distribution as a function of MDF fiber size by laser scanning microscopy. Wood Sci Technol 37:495-507. https://doi. org/10.1007/s00226-003-0195-3 
Zickler GA, Schöberl T, Paris O (2006) Mechanical properties of pyrolysed wood: a nanoindentation study. Phil Mag 86:1373-1386. https://doi.org/10.1080/14786430500431390

Publisher's Note Springer Nature remains neutral with regard to jurisdictional claims in published maps and institutional affiliations. 